\title{
Global pandemic, local solidarity: Six civic initiatives from Leipzig, Germany
}

\author{
Micha Fiedlschuster (michaf@yorku.ca) \\ York University, Canada \\ Leon Rosa Reichle (leon.reichle@posteo.net) \\ De Montfort University, United Kingdom
}

In this article we contribute to the mapping out of overall solidarity responses from below to the pandemic by giving local insight into the varied forms of neighbourly support groups in Leipzig, Eastern Germany. Having followed the trajectories of six groups between May and September 2020 with eleven semi-structured interviews, we highlight different organizational approaches, understandings of solidarity, normative horizons, transformative aspirations and practical barriers to these aspirations. We analytically map out the groups with three different sociological conceptions of solidarity (solidarity based on shared identity, as a moral duty or as a transformative political practice) and highlight their blurry boundaries in practice. We tentatively assess the transformative potential of the groups' activism and reflect on it in relation to their socio-spatial locations within the city.

Keywords: COVID-19, solidarity, civil society, social movements

\section{Introduction}

The global pandemic COVID-19 not only triggered a global health crisis but also initiated horizontal support and solidarity around the world (Sitrin \& Colectiva Sembrar, 2020). In many cases this was organized through existing social movement networks and civil society structures but also new ad hoc groups formed, specifically dedicated to neighbourly support. Together with the existing networks, they mobilized solidarity potentials in society.

Recently, academics and activists have begun to map out the variety of solidarity activism and the newly emerging or intensifying problems people have faced around the world (Chattopadhyay et al., 2020; Sitrin \& Colectiva Sembrar, 2020). With this article we aim to contribute to this endeavour. Yet instead of providing a general hopeful or pessimistic overview about a (geographically) wide range of initiatives, we unpack a few cases of local practices of solidarity in order to map them out analytically.

We do this by assessing the diversity of bottom-up initiatives in the city of Leipzig and their overall practices of solidarity as responses to the economic and social consequences of the pandemic and the lockdown. A first short assessment of solidarity initiatives in Leipzig was published in June (Fiedlschuster \& Reichle, 2020) and reflected from an activist angle in August 2020 (Reichle, 2020a). In the present article, we seek to expand our analysis.

As Lesley Wood (2020) has pointed out, "we're not all in this together" because the crisis and the accompanying political measures affect people very differently depending on deeply ingrained social inequalities. Drawing on Wood's claim, we are curious about the extent to which the initiatives address these stratified consequences of the pandemic. Therefore, we discuss three different sociological conceptions of solidarity (solidarity 
based on shared identity, as a moral duty or as a transformative political practice) providing a lens to analyze the groups. Our goal is to point out the similarities and differences between the initiatives as they relate to these three conceptions of solidarity. We seek answers to the following questions: How were new groups formed and did existing groups change their agenda and organization? How is solidarity defined and organized? Which normative and political backgrounds motivate the initiatives? What is the temporal horizon of their work and how did the groups change over a six-month period?

We found that the initiatives offer similar services and use similar organizational tools, and even share the common problem of limited reach. However, this problem is addressed differently by each group depending on their political motives and normative foundations. Furthermore, we see a correlation between the differences in the groups' transformative will and the socio-economic geography of the city. Having followed the initiatives over several months, we complement an analysis of the groups' initial aims with their actual trajectories. This enables us to contribute to an early discussion around the temporality of bottom-up initiatives and involved social movements (Pleyers, 2020).

In contrast to Pleyers, who hypothesizes that the current crisis will result in a global wave of movements, we have found that despite the high mobilizing potential of the COVID-19 pandemic, the solidarity initiatives within the city of Leipzig currently do not point towards a cross-sectoral solidarity movement that addresses the social problems exacerbated by the pandemic. Despite some groups' reflective attempts to develop long-term strategies and projects, their work at present remains, by and large, within rather limited activist or socio-economic circles. Yet we agree with the editors of Pandemic Solidarity, that "movements are not linear, and change must be thought of in non-linear ways" (Sitrin \& Colectiva Sembrar, 2020). Hence, from the current point of view, we can offer no concluding judgement on the long-term transformative nature of the initiatives in Leipzig. Instead, we offer a small insight into the spatio-temporal variety of solidarity initiatives and their transformative aims and potentials within the city.

We begin with a short overview of theoretical concepts of solidarity, providing a lens to analyze the solidarity initiatives. Second, we introduce our methodology and data before discussing six cases with differing political backgrounds and organizational setups. Finally, we examine different trajectories of bottom-up COVID-19 support and the impact of the pandemic on those groups that existed before COVID-19. Concluding, we resume the shared problem of limited reach, discuss potential explanations and close with a hypothesis about the relationship between Leipzig's socio-economic spatiality and different forms of COVID-19 support.

\section{Three types of solidarity}

There are many ways to classify solidarity (for example Kavada, 2020; Schwiertz \& Schwenken, 2020). In this section, we introduce a three-dimensional sociological typology of solidarity to guide our empirical findings. We present a few international reflections on solidarity responses to COVID-19 to highlight the theoretical distinctions, although, as we will show empirically, these distinctions are often blurry.

\subsection{Solidarity as compassion and a moral duty}

Hegemonic views of "coronal solidarity", such as called for by the German chancellor in her address to the nation on March 18,2020, have been recently problematized by August (2020) as limited to acts of solidarity as compassion and a moral duty. This form of solidarity aligns with charity and Christian values. Its advantage is that it has a huge mobilization potential because it refers to values deeply ingrained in European societies. Yet it is also this apparent moral matter-of-factness, that gives compassionate solidarity potential regulatory power and earns it criticism. Any behaviour diverging from the moral compass of 
compassion threatens to be sanctioned. Furthermore, this type of solidarity "follows the more hierarchical model of charity as it makes a clearer distinction between those who are vulnerable [...] and the volunteers who help them" (Kavada, 2020). Nevertheless, as Nuss (2020) proposes, acts of compassion can serve as an appeal for taking responsibility for one another, and hence a "social glue" in a fragmented society.

During the first wave of COVID-19, acts of compassion have often filled the void of closeddown charity organizations, or they were organized by institutionalized actors themselves like Kavada (2020) presents in an example of the government-sponsored NHS Volunteers Responders Service in the UK. This type of support work can be characterized as an act of welfare that does not question existing structures and relations of dependence, and thereby risks perpetuating them. This logic stands in contrast to mutual aid networks built on reciprocal relationships emerging through a common concern, experience or struggle. Therefore, even if solidarity as compassion and moral duty can be a powerful source to mobilize help, as the high numbers of volunteers testify, we argue that this type of help can neither cover up nor challenge the stratified, physical and economic consequences of the pandemic.

\subsection{Solidarity as shared identity}

Solidarity as (or based on) shared identity was similarly critiqued as potentially exclusive, most notably in the context of COVID-19 (August, 2020). This critique is based on readings of Richard Sennett who warns of anti-democratic consequences of solidarity. First in The Uses of Disorder and then throughout his writing, Sennett (1973) has condemned community solidarity as a purification tool aiming for homogeneity and glossing over differences in a shared 'we'. Different assessments of solidarity based on a shared identity clearly depend on the vast range of theoretizations of identity, the analysis of which would go beyond the scope of this article (for an overview see du Gay et al., 2000). To highlight the complexity of identity-based solidarity in practice one must ask to which extent identity is fixed and which shared experiences form its basis?

An exemplary solidarity initiative built on common experiences of women facing structural discrimination during COVID-19, and hence female perspectives and identities, is the feminist online activism in Wuhan against increased domestic violence during the pandemic (Bao, 2020). Yet this could also be a very heterogeneous form of activism, depending on its reach, intersectionality and inclusiveness. Moreover, as it is the case in our examples, most initiatives implement strong privacy rules, which means that they have little information about the identity of the persons that they help.

In contrast to Sennett's and August's critique, social movement scholars have highlighted the strength of temporary, heterogeneous and always shifting solidarity movement coalitions (Mühe, 2019). Their shared identity is temporary and flexible as well as built on overlapping experiences or practices. Analysing the solidarities between civil society groups and migrating and racialized people, Schwiertz and Schwenken $(2020,405)$ point out that "inclusive solidarities arise through collective practices, the emergence of new subjectivities, and the mediation of difference."

Following our analysis, a shared identity at the base of one initiative's political mobilization before the Corona crisis did not lead to exclusive solidarity.

\subsection{Solidarity as a political practice}

Solidarity based on a shared identity can overlap with solidarity as a political practice. Drawing from feminist literature, Bargetz and colleagues (2019) argue that "contextualized, historically specific" solidarity struggles can build connections by using differences productively rather than understanding these differences as obstacles. Della Porta (2020) is witnessing the emergence of ties between progressive social movements during COVID- 
19 and hoping for their political potential beyond it. In line with a tradition of anti-colonial and black feminist scholarship (hooks, 2015), radically pluralist and transformative perspectives are those critical scholars and activists work towards (Reichle \& Bescherer, 2021; Reichle, 2020a). From this perspective, solidarity is defined as a shared struggle against oppression (Featherstone, 2012), a struggle for the same goals, positioned against something or someone specific (Nuss, 2020) or, on more universalist terms, based on an analysis of a concrete universalism implying that all are concerned differently by the same oppressive society (Adamczak, 2018; Meißner, 2015; Mühe, 2019; Struwe, 2019). Anastasia Kavada (2020) stresses that the creation of a "hyperlocal infrastructure of care" likewise can have politically transformative potential through building community ties and resilience that later can facilitate political organization.

As we show below, these different variations help to analyze the temporal and political differences of the solidarity initiatives in Leipzig.

\section{Please, let me help you: Six cases of solidarity}

In Leipzig, a city of 600,000 inhabitants in Eastern Germany, the number of infections was relatively low between May 10 (585 cases) and September 30, 2020 (912 cases), the timeframe when interviews were conducted (Robert Koch Institut 2021). Yet the social and economic consequences of the pandemic were palpable. On March 17 all public events were banned and a week later an almost complete lockdown came into effect. It was partially lifted on April 20 and public life re-opened with restrictions on May 4. The city returned to a new normalcy during the summer with differentiated restrictions and a relatively low health risk for the population before the second wave of Coronavirus cases started in October 2020. Like most cities, Leipzig was caught off-guard by the pandemic. The municipality focused on enforcing and communicating the restrictions, monitoring the cases and communicating the development of the pandemic to the public. The local health office's phone line offered information about the coronavirus and the situation. Our interview data suggests that the public health office referred people in need of support to at least three of the initiatives that we interviewed (the foundation Ecken Wecken, BSG Chemie, and Nachbarn für Nachbarn). This is significant as it speaks to the fact that at least some of our initiatives were known to the health office. Having said that, no attempts were made to make the initiatives an integral part of the administration's response to the pandemic and they are, for example, not visible on the city's webpage about the Coronavirus. The solidarity initiatives thus formed independently from state-organized responses and without the city's direct financial or organizational support (an exception is the foundation Ecken Wecken, who received some funding from the city at the end of 2020 to improve their software, see Stiftung Ecken Wecken, 2020). Keen to understand their practices and witness this real time social experiment, we plunged into a small, qualitative research project. Our methodology was coined by a "historical moment of potential constant change and unforeseeable consequences [demanding] a certain flexibility and messiness" (Reichle, 2020b). Because we expected the lockdown to be short, we wanted to cease upon the moment when the initiatives were active and the experiences of the interview partners fresh. We are aware therefore that this methodology could result in flaws in the research design and that there could be limitations of the gathered data. This means that the conclusions we draw from our data, while they can inform more comprehensive studies, should also be considered preliminary.

We conducted six semi-structured interviews during May 10th and 15th and five followup interviews between August and September 2020 with different civil society initiatives. All interviews were conducted and transcribed in German. Quotations are translated by the authors and all names appearing in the article are used with the interviewee's explicit consent. The interviews are referenced in the following format: IP1 stands for the first 
interview with Poliklinik. Follow-up interviews are indicated with the number two. IC refers to the group BSG Chemie (only one interview); ID to direct.support Leipzig; IE to the foundation Ecken Wecken; IL to Leipzig Solidarisch Ost; IN to Nachbarn für Nachbarn.

Due to the social distance rules, the interviews were conducted by phone or in public space with physical distance. In some cases, group discussions would have been more appropriate to capture the group dynamics, but these were unfeasible in the pandemic situation. The interviews were anlayzed using qualitative content analysis (Mayring \& Fenzl, 2019). First, the material was categorized along different theories of solidarity and then the categories were refined according to the material.

Our selection of interview partners was based on our interest in varying grades of institutionalization and political orientation. We wanted to learn about the initiatives' organizational setup (including organizational challenges and barriers to distribute help during the lockdown), the group's temporal horizon and development, networking activities, and the group's understanding of solidarity. The follow-up interviews provided important information about the groups' trajectories after the end of the lockdown and gave us the opportunity to confirm or challenge our previous analyses.

At first glance all initiatives seem to be similar in action and reach: They encourage neighbourly help with practical daily life tasks that are complicated either through the virus itself (especially for high risk groups) or the respective lockdown measures. Another shared aspect is their limited reach: Compared to the population of the city and the expected need, few people use their services. Yet we have found differences between the initiatives in terms of their ideological framework, the organizational philosophy, the target groups, and the time horizons of action. We discuss these differences alongside the aforementioned conceptualizations of solidarity.

\subsection{Mobilizing a shared identity for universal support}

The blurry boundaries between solidarity based on shared identity and solidarity as a political struggle highlighted above also manifest empirically. One initiative in particular has grown out of a shared identity: the legal-help collective of the local soccer club BSG Chemie. After briefly introducing the group, we narrate the trajectory of their solidarity activism as an exemplary case for the shifting nature of solidarity in action between shared identities, compassion and political critique.

The legal-help collective was formed in 2014 as a response to harsh police brutality towards fans and ultras of the soccer club as a "solidarity community that supports fans that, in the widest sense, get into conflict with the law" (IC). With the outbreak of COVID-19 and the ban of large public events, their work in the stadium came to a halt and they contemplated how to use their network in the emerging crisis. Their aim was "to come out of the crisis strengthened, initially the idea was [only] for the Chemie fans" (IC). They became active in line with their basic principle of solidarity, which "means that we are there for one another within the fan-scene [...] and support one another" (IC). Our interviewee's perspective demonstrates the strong shared identity at the base of the group's activism which initially seemed to exclusively target other fans.

In the second half of March, a core group of ten to fifteen fans decided to take action. They started out by creating chat groups among the fan scene in the different parts of the city: north, east, south and west. They designed leaflets offering practical help to people in quarantine or risk groups and distributed them. Their existing phone hotline was repurposed as a helpline for this new form of activism. When receiving a call, they anonymously posted it in the respective group, depending on a person's location. In the south, where many of their fans live, the group "became independent quickly" (IC) and in the west and east connections to existing initiatives were sought. The activism therefore quickly lost its centralized organization and was carried on (to a large extent) locally. 
The initiative was soon approached by the local public health department. Confronted with phone calls from citizens about how to deal with daily life tasks during the restrictions and in some cases quarantining, the department referred requests to BSG Chemie and other solidarity initiatives. The pragmatic cooperation with the municipality provided the initiative with the majority of their help requests. Overall, these still remained few. Accordingly, they adapted their focus: "It got a bit more global, throughout the whole city and outside of the scene." (IC) Their highlight was supporting a poor family in quarantine and organizing Easter presents for the kids: the group's large network gathered such a massive lot of presents that they had enough to redistribute it to several refugee shelters and to the local food bank.

The Chemie-fans were not discouraged by the low demand; instead they kept adapting their work, for instance through encouraging blood donations (which went down during the pandemic) and asking people to donate the remuneration to food banks or the local women's shelter.

The legal-help collective's solidarity exemplifies how solidarity based on a shared identity can turn into a more universal project. Their solidarity is shaped by compassion: "In the fan-support we simply like to support people and [...] have an inner drive to do so" (IC), but also a political critique. In addition to their pragmatic help, they continued their critical evaluation of state measures: "We also wrote texts on how to deal with constraints of freedom and observe many policing measures critically." (IC)

\subsection{Compassionate solidarity}

The group Nachbarn für Nachbarn (Neighbours for Neighbours) operates in the quarters Schleußig and Plagwitz, the former being one of Leipzig's few central middle-class neighbourhoods and the latter becoming one too. First, we describe the organizational setup and working mode of the group. Second, we discuss the self-proclaimed non-political character of the group, which did not prevent conflict. Finally, we describe the practised neighbourly support as a form of solidarity as compassion. The interview partners stressed that they felt an obligation to help but that they preferred to do it in a non-political way. In contrast to the foundation Ecken Wecken, direct.support or Poliklinik, they did not see the pandemic as an opportunity to mobilize for social and political change.

Nachbarn für Nachbarn's structure is perhaps exemplary for neighbourhood groups that were created as an ad-hoc response to the crisis by citizens who mostly did not know each other before. When uncertainty about the pandemic rose in late February, one person started a call for organization in the social network nebenan.de, which connects residents in the neighbourhood. The call led to an initial meeting of about 12 persons. They decided to set up a Telegram chat group for coordinating help and a phone line as an access point. The service was made public mainly through flyers. Their main target group were the elderly whom they identified in accordance with the public authorities as those who need help most. The group responded to an estimated eight requests mainly about grocery shopping until May 2020. Because of the reorganization of the group (see below) and the lifting of the lockdown in May, the group reduced its activity and went into a stand-by mode.

The group's working mode can be characterized as helping without organizational or political attachments. Friedrich, one of the two interview partners in May, emphasized that they had no intention of either setting up a fixed organizational structure or engaging in political work. For the latter reason, the group turned down requests for networking by groups in Leipzig. Friedrich explained that many groups in Leipzig have a left agenda which would not fit Nachbarn für Nachbarn's decidedly non-political character and the group's composition, which he described as politically and socio-demographically diverse. 
For pragmatic and time reasons, they decided against a social media strategy. They also assumed that their target group-the elderly-does not use social media. Also, social media would require guidelines and organizational structures, complicating the consensusfinding process in the group.

The group sees internal discussions as detrimental to the organization of help. The about 30 members practice a form of direct democracy: Every group member can post a question in the chat group, which is then discussed by everyone who wants to participate. If a majority position emerges, it is implemented. This is an informal process of a majority vote. The non-political setup of the group did not save them from a significant conflict. The initiator posted political messages in the group and organized protests against the government restrictions. These protests are associated with conspiracy theorists and the new right. At first, the group tried to discipline his activity by asking him to stop posting political messages within the group. When he did not follow their request, tried to obtain a leadership role, and when the group became associated with his political activities in the eyes of the public, the members decided to create a new group under a new name and thus excluded the initiator from its ranks. The conflict within this group can be understood as reflecting the growing polarization within the broader population itself around the appropriateness of restrictions. Interestingly, this conflict, both within the group and within the broader society, is not between the left and the right but rather between the political mainstream and the new right.

The group's solidarity can be characterized as a form of compassion or felt responsibility for people in need. The two interview partners pointed out that their Christian world-view was a source of motivation but this was not generalizable for the group which they characterized as being diverse. They wanted to avoid labels in order to be as open and approachable as possible and to avoid in-group conflicts. When asked about the term solidarity, Friedrich said that the core idea of solidarity is to help the needy, which he saw as their source of motivation. However, they did not use the term because it is used by other groups in Leipzig and because of its socialist legacy. Charity, altruism and a moral duty to help are more accurate to describe the group's ideational framework than solidarity. In contrast to the groups introduced in the next section, the practices of Nachbarn für Nachbarn did not challenge the political-economic system or the respective socially unjust, stratified consequences of the pandemic. Yet we argue that unlike the group's self-definition, this is by no means an apolitical stance, but one that (passively) affirms the political status quo.

\subsection{Solidarity as transformative political practice}

In this section we differentiate between two types of politically transformative solidarity. By introducing the four remaining groups interviewed, the foundation Ecken Wecken (Awaking Corners), direct.support, Leipzig Ost Solidarisch (Leipzig East Solidarity) and the Poliklinik, we distinguish between reformist and radically transformative approaches to solidarity.

The foundation Ecken Wecken (2020) is located in the Western part of Leipzig and was founded in 2009. Its mission can be described in terms of community capacity building. In the development sector, capacity building describes the development of a community's ability to achieve its goals more effectively. In the foundation's most prominent project, the citizen railway station (Bürgerbahnhof), a former railway area was developed into a space that citizens can use in many different ways (urban gardening, sports, playgrounds, graffiti and more). The foundation mediated the interests between the municipality, local politicians, local businesses and the residents in the neighbourhood. The foundation pursues a collaborative approach with the city administration and developed forms of democratic participation in urban planning. The foundation's work is a form of democratizing 
representative democracy because it seeks to increase citizen participation in the existing political system (Fiedlschuster, 2018, 245).

In the following, we discuss the foundation's project Corona help (Corona-Hilfe) in conjunction with our research questions and three themes that were prominent in the interview with Thorsten, the head of the foundation: First, efficiency and professionalism in the organization of aid; second, expansion of the service and long-term perspective; third, improving the state-civil society relationship.

Due to the lockdown, the foundation was not able to work on their existing projects but they quickly saw, as Thomas expressed it, that something had to be done during the crisis. Neither did they have to change their agenda, which is bringing together citizens for a common goal, nor did they change their working method significantly, which is facilitating organizational processes efficiently through mediation and technology.

Like other initiatives the foundation set up a website and a phone line, which they advertised with posters in the city. Specific here is the use of a constituent-relationship management software that is used by organizations in the non-profit sector. The software enabled them to coordinate help efficiently with a small team. Thorsten explained that they needed 25 minutes to respond to a request and that they wanted to bring it down to five minutes response time. On June 17, 2020 they counted 1,124 supporters across the whole city and had answered 244 calls for help since they started on March 15, 2020 (In 142 phone calls a person in need was matched with a helper). Via a geo-tagging function, the foundation can easily find registered helpers nearby a person in need.

When Thorsten was asked how they seek to reach more people in need he referred to the media strategy. Because they were among the first initiatives in Leipzig, they received some media attention. They used it to increase the acceptance of help rather than asking for more helpers. Thorsten explained that one obstacle seemed to be that people hesitated to accept help. He said that no one in our society wants to be labelled as needysomething he experienced already in past projects.

The foundation has applied for money to improve their system further, to develop a system that can be used in other parts of Germany, and for future crises (in December 2020, the municipality provided a grant to enhance the foundation's software). The intent to expand shows that the foundation understands itself as a professional non-profit service provider.

Whereas Ecken Wecken seeks moderate social change and aims at becoming recognized by the local authorities and politicians, the next group set up a state-independent redistributive system.

Direct.support Leipzig (2020) which is modelled after groups in Berlin and Halle, connects people in a financial crisis with people who have money to spare. They set up a simple and anonymous network of redistribution: someone who self-identifies as being in financial difficulties (they explicitly encourage people who are exposed to structural discrimination) contacts the group. The group organizes what they call 'bidding rounds' in a Telegram group to collect the money. The supporters receive the bank account number (but not the name of the account holder) and send the money directly to the person. They started in March 2020. At the end of the year, the group distributed approximately $13,000 €$ (direct support leipzig, 2020). The process is as anonymous as possible to protect the people in need, which raises the question of how to foster long-term relationships among the participants (except among the organizers) and how to go beyond a mere monetary redistribution. Nevertheless, they tried to fill a gap in the allocation of state-run emergency funds, which turned out to be inaccessible to some needy groups of persons.

Direct.support is a solidarity redistribution network. One of the interview partners characterized solidarity in the following way: "Not all people have equal chances and possibilities, not all have the same starting position, which can be clearly seen in the crisis, which shows 
that some are hit a lot harder. Responding with solidarity means to take such inequalities into account." (ID2) The person pointed out that solidarity is about "a collective dealing with the problematic situations created by the system, which means that it is not an individual-'you are responsible' - question and people are left alone with the problem. Instead, one has to think about the systemic level and to say 'it is not your fault, let us collectively take responsibility.'" (ID2) Direct.support's understanding of solidarity is tied to a systemic critique of capitalism and the existing political system that creates or perpetuates inequalities. Solidarity to them is a political practice to tackle inequalities collectively.

Some of the members of direct.support had also been part of the large Telegram chat group Leipzig Ost Solidarisch (Leipzig East Solidarity), counting 860 members in May 2020. We introduce this group as another example of radically transformative ideas, whilst highlighting the limits of their activism in practice.

The chat group was set up by three friends who self-identify as "politically engaged people" (IL1). Interviewing one of them, we learn that the group emerged out of the attempt to find a way to adapt political activism to COVID-19 and the restrictions which accompanied it. As the group rapidly grew beyond the initiators' expectations, they met in the park to coordinate its moderation and to define a code of conduct. Initially the aim was "to collect ideas, how we can support those that suffer most, locally in the neighbourhood: that means refugees, people without housing, those affected by domestic violence or the ones overwhelmed by childcare" (IL1). Practically, this meant spreading templates for placards to offer neighbourly support, sharing inspirational leaflets from groups in other cities, and also posting comics for kids explaining COVID-19, and flyers with hotlines for victims of domestic violence.

Yet, "after two to three weeks we became aware of our major challenge, we realized that our potential is limited to address people that belong to risk groups. We noticed that our chat group stayed within the scene and we couldn't reach those we wanted to reach." (IL1) This problem of reach led to the pragmatic subdivision of people into more institutionalized voluntary work and emerging specialized groups. Some people self-organized collective child-care, others followed a call by the local hospital, several joined the emerging direct.support initiative described above and a few started an initiative of gift-fences for homeless people. The organizers' reflection on their limited reach beyond activist cycles, despite the overwhelming size of the chat group "made us question how political work can better reach the people it refers to" (IL1).

The motivations and transformative horizons in this large chat group can be expected to be very diverse. Some people joined charitable initiatives with no explicit transformative perspective, like the food banks or the gift fences. Others formed into the redistributive direct.support group. The spontaneous, diverse nature of the chat group and several changes of tactics make it hard to classify and point to the blurry boundaries of solidarity in practice. For the organizers, solidarity has a clear political dimension. Yet, the transformative horizon of their spontaneous, rather unorganized project remains unclear. They define solidarity as "unconditional mutual support based on a perceived form of injustice, and it is not limited to any group membership" (IL1).

The organizers of Leipzig Ost Solidarisch quickly established a cooperation with their friends from another initiative that we interviewed, the Poliklinik. After an introduction of the last group and their actions, we follow the emphases of our interview partner concerning their limits of reach and inner-group dynamics, and then conclude with our assessment of its radically transformative horizon.

With a core group of 15 to 20 people from different medical and social professions, the "solidarity medical centre" (IP1) Poliklinik was supposed to open in March 2020. The idea behind this clinic is "that you can only change health via social conditions-we think that social determinants make you sick, like housing conditions, working conditions, racism" 
(IP1). Therefore, they explicitly chose the working-class neighbourhood Schönefeld as their area of activity "because people here are maybe more marginalized than [elsewhere]" (IP1).

After a time of resignation about the interruption of their work through the pandemic, the group founded a specific COVID-19 task force. It took action within the neighbourhood through establishing a phone line, organizing and distributing self-made masks and translating and spreading informational material about the governmental restrictions. Their activities were targeted at "simply the normal neighbourhood" (IP1) and, more specifically, at people who are not fluent in German and hence unaware of the constantly shifting restrictions. To tackle their problem of a limited reach, they started extensively putting up leaflets and spread the number of their newly established phone line.

Whilst receiving many support offers, their assessment was that "like in all other groups" (IP1), demand for help was quite low. "Especially elderly people sometimes eye us critically, this new left-wing project, and maybe, I'm not sure, people in need sometimes find it even harder to accept help [...] or it's simply distrust." (IP1) In a neighbourhood marked by slightly above-average support of the far-right party Alternative for Germany ( $A f D)$, which has been prominent for anti-refugee protests in the past years (Reichle \& Bescherer, 2021), this might be a question of political adversity, yet the interview partners did not bring this up directly. Yet, they were happy to have done so much publicity work and were astonished by the positive feedback they received, especially by employees of refugee shelters for the translation of information.

Within the group, they could feel the stratified effects of COVID-19, depending on childcare duties and other restraining factors. Additionally, the fact of not being able to see one another "somehow paralysed the group a bit" (IP1). At the same time the quick active adaption to the situation permitted the group to "grow from the situation" (IP1). They started an internal psychosocial support group and learned to make decisions faster than ever before.

As the Poliklinik existed with a distinct goal before COVID-19, its radically transformative approach is probably the clearest within the interviewed initiatives. The interview starts with the activist stating: "We are a political group, we do political work." (IP1) She further explains the long-term emancipatory nature of the project: "We want to support solidarity neighbourhood help, so people get empowered, especially in times of such intense isolation [...] we want to build structures and simultaneously utter our criticism because we are now doing the work that should actually be done by the state." (IP1) That the project is locally grounded but concerned with global problems, manifests in their understanding of solidarity: "Generally we work against an unjust system where the responsibility is dumped off onto the individual. But of course, we're changing that on a small scale, we won't manage to change the whole system - unfortunately (laughs)." (IP1)

To sum up, the foundation Ecken Wecken hopes for reforms in the established political system of representative democracy, whereas the work of direct.support, Leipzig Ost Solidarisch and the Poliklinik are linked to more radical critiques of the current system. They all interpret their COVID-19 support as a tool within a wider struggle against oppression and social injustice, wanting to de-individualize responsibility. Yet the nature of their practical interventions varies. While the chat group Leipzig Ost Solidarisch formed the base for very diverse projects, direct.support is still in the making and the impact of the pandemic on the Poliklinik's transformative, long-term perspective and work remains to be seen. 


\section{Different trajectories of support initiatives: The pandemic's impact on solidarity activ- ism}

The development of COVID-19 had a variety of impacts both on newly emerging and longterm initiatives. (Unfortunately, we did not reach the legal-help collective of BSG-Chemie a second time. The group Nachbarn für Nachbarn does not intend to organize beyond the pandemic. For these reasons both groups are not included in the analysis.) Central themes in the interviews were the up- and downsides of digitalization, the groups' outreach-problems and the question of normality.

Our interviewee from Ecken Wecken expressed a longing for returning to normalcy, as not all activities were feasible online. Also, members of the Poliklinik have struggled with the situation: "It really thwarted us. We needed a long time to get the group together afterwards [...] and this time [...] tattered us quite a bit (laughs)." (IP2)

To a varying extent, the long-term initiatives saw potential in the progressing acquisition of digital tools. Dreading potential future outbreaks, our interviewee from the Poliklinik reluctantly stated that "maybe we will be better trained with these [online skills]" (IP2) when a second lockdown comes in the way of their work again. Ecken Wecken in contrast, enthusiastically incorporated a digital approach into their long-term perspective, hoping to create a sustainable platform for neighbourly help beyond the COVID-19 crisis. Through this they hope to promote a general "digitalization of civil society" (IE2). This comes across both as a main aspect of their transformative horizon of facilitating neighbourly engagement and as a marketing strategy for their group.

Whereas Ecken Wecken could benefit from the situation through acquiring new members and wider visibility, the Poliklinik's team was confronted with the limits of digitalization. Along with their status as a relatively new institution in the neighbourhood, they had trouble reaching their target group. Yet a reflection of this encouraged them to initiate a special neighbourhood task force. This subgroup is now planning to conduct activist interviews in the neighbourhood to enquire "how people have experienced it [COVID-19 and the lockdown], how have they noticed us" (IP2), and increase awareness for their clinic. A major difference in the (digital) outreach of both groups presumably lies in their socio-spatial location within the city (and its population). Ecken Wecken has especially evaluated their success in terms of new members that had signed up to help, estimating that a majority was younger than 30 , with only a fifth becoming active due to the low demand. This is not surprising with their centre of action located in the gentrifying West of the City. The Poliklinik on the other hand, located in a predominantly working-class neighbourhood, had difficulty reaching out through the use of technology to their target group of economically precarious and marginalized neighbours.

For the founders of the newly founded chat group Leipzig Ost Solidarisch, the outbreak of COVID-19 and a retrospective reflection on their actions brought a similar issue of reach to the forefront. For them, as individual activists engaged in a variety of projects, the experience has "opened up new aspects [...] regarding lacking connections between people who want to build solidarity structures and the needs of people in precarious situations [...]. I think that shook us up a bit." (IL2) This new consciousness about the often self-referential nature of their previous activism has encouraged them to explore the flaws and potentials of different (digital) means of communication.

Lastly, the experiences of the redistributive initiative direct.support with the rise and fall of COVID-19 outbreaks was counter-cyclical to that of the other initiatives. Instead of hoping for normalcy, the two activists interviewed realized that "in our group everything seems to be constantly changing, so normality doesn't really exist" (ID2). For them, decreasing infections implied less awareness and diminishing legitimation for their project. Because "for some people it [COVID-19] is definitely still visible, for others it isn't. But because we rely on people, for whom it's less visible, to donate money, it is harder for us [...]. 
That's a challenge, less and less people give money to those who need it." (ID2) Wanting to create a long-term redistributive mechanism, they were confronted with the fading out of people's exceptionally charitable willingness to contribute during the first peak of the crisis. As a response to this challenge they decided to invest more time in educating people about capitalism, the current system and why it fails some people on the one hand, and about solidarity economy on the other. In addition, they are planning to increase their networking activities to reach more people.

\section{Outlook}

In this article we have analyzed the differences and commonalities in the practices of six solidarity initiatives during the first wave of COVID-19 in Leipzig, Eastern Germany. Additionally, we have followed the initiatives' trajectories to understand the temporality of their work and the impact of COVID-19 on solidarity practices.

The different forms of activism have been important to cater to specific people in need, be this the affluent elderly in Schleußig or the manifold precarious workers all over the city who were temporarily unable to pay their bills. Whereas Ecken Wecken, with their pragmatic, technical approach and their publicity through previous work, was able to carry out a somewhat larger number of help transactions, the quite young groups in the city's East were confronted with barriers of (digital) communication, scepticism among the elderly and lacking "bridging social capital" (Putnam, 2000) within the neighbourhood. Despite slight differences, all initiatives shared the problem of a limited reach among those to whom they wanted to offer help.

As one interviewee reasoned, no one in our society wants to be unable to perform or wants to be seen as needy (IE1). This might be a consequence of a meritocratic society of "competitive individualism" (Littler, 2013, 52). Although often internationally admired for its welfare state, German post-war ordoliberalism can be counted as a very early implementation of neoliberal ideas (Haderer, 2018). In combination with a Christian Democratic conservative family ideology the ordoliberal logic promoted state-guaranteed maximum economic competition, hand in hand with government support of the nuclear family, securing consumption and delegating social reproduction to the (feminized) "private sphere" (ibid.). With German reunification this ideology was transferred abruptly to East Germany as well. Exacerbated by the 2005 labour-market reforms (Hartz-reforms), this individualization of reproductive responsibility can be expected to have a strong detrimental effect on people's willingness to admit vulnerability or accept help from strangers, especially among a generation of elderly in Eastern Germany, having experienced a massive economic breakdown and years of discrimination (Buck \& Hönke, 2013). Whereas our data do not permit us to generalize about people's reactions and attitudes toward solidarity initiatives, the perspectives of the activists indicate a lack of trust among the general population. To what extent this is related to a neoliberal subjectivation of competitive individualism (Belina, 2020), remains a theoretical question that needs further empirical inquiry.

Beyond the commonality of a limited reach, our analysis of the solidarity initiatives groups, their ideals, aims and practices, has revealed important differences regarding practical, political, spatial and temporal dimensions of their work.

Mapping the groups with a typology of solidarity theories has revealed their different temporal and political horizons, but also captured the blurry and shifting nature of solidarity in action. Whereas the shared identity seemed an obvious base for the solidarity activism of specific soccer fans, their work became more inclusive over time, was shaped by compassion and accompanied by vigilant and critical observation of the governance of COVID19.

Meanwhile, a shared identity is no outspoken motivator for any of the other group's work, yet their very different political characters stand in an interesting relation to their location 
within the city. Whilst our small sample and the exploratory nature of the project does not allow concluding remarks on this, different hypotheses about the spatiality of supportwork have arisen throughout the interviews and in our analysis. It is noticeable, that the explicitly non-transformative, and self-declared a-political group (Nachbarn für Nachbarn) emerged in one of the wealthiest inner-city neighbourhoods (Schleußig), and the reformist one (Ecken Wecken) in a largely gentrified, adjacent district, whereas two of three groups with a more radically transformative horizon (Poliklinik, Leipzig Ost Solidarisch) are located in the much poorer East of the city where living costs are (still) lower. Along with direct.support, these groups seem to share the most radically left-wing political stance, which matches the recent history of their neighbourhoods, witnessing an influx of financially precarious (yet mostly academic) left wing activists in the last years. The city's South, in contrast, while gentrifying, still holds the longest left-wing tradition and is the base of many left-leaning soccer fans (BSG Chemie). These, along with activists from other groups, have also remarked the void of similar activities groups in the north, which has not been known for a left-wing political tradition or subculture in the last decades. The groups' spatial and political locations are in line with the extent of cooperation among the groups: The initiatives on the left seem to cooperate among each other, yet this is partially simply contingent on existing friendships and networks between individuals in the group. Without naming specific initiatives, they defend solidarity activism as "a traditionally left-wing perspective" (IP1), and distanciate themselves from conspiracy theories. In turn, the members of the explicitly a-political group (Nachbarn für Nachbarn) keep to themselves and avoid politically charged vocabulary of the left such as 'solidarity.' These observations raise the question, to what extent there is an undiscussed shared (class and political) identity, or at least a common experience of one's location in the city, and therewith society (Joseph, 2002) at the base of some of the groups' work and horizons of social change.

The groups' socio-spatial location within the city and its population has also impacted their strategies and ability to deal with the pandemic situation. Whilst mobilizing middle-class young helpers online was an easy way to increase the publicity of groups like the foundation Ecken Wecken, the groups in the poorer East (Poliklinik and Leipzig Ost Solidarisch) were confronted with the limits of digital communication among their economically precarious and marginalized target groups.

The newly founded direct.support group was confronted with the downside of pandemic solidarity, yet not in terms of its charitable, but its transient nature. Trying to build a longterm redistributive project when the short-lived attention for the pandemic had evaporated among donors encouraged them to focus on structural social inequalities: "Therefore it's even more urgent to condemn these basic principles along which our society is constructed!" (ID2)

To what extent any of the groups' work is not just immediately charitable and efficient, but also sustainable or maybe even transformative for the city's social and political life remains to be seen and will depend crucially on the reach and the relationships these groups manage to build within the local population. We have given a temporally specific insight into varying transformative aspirations and highlighted existing social barriers to these. Yet, as the Colectiva Sembrar (2020) has noted, social change is no linear process and the post-pandemic future remains unwritten. 


\section{References}

Adamczak, B. (2018). The Double Heritage of Communism to Come: 1917-1968-2018. Communists in Situ.

August, V. (2020, April 23). Gegen Solidarität! Zwei Modelle sozialen Zusammenhalts und die Corona-Krise. theorieblog.de.

Belina, B. (2020). Political geography lecture: Social forms, spatial forms, and the New Right. Celebrating Capital at 150 and explaining the rise of the AfD. Political Geography, 81, 1-9.

Bao, H. (2020). Anti-domestic violence little vaccine: A Wuhan-based feminist activist campaign during COVID-19. Interface: A Journal for and about Social Movements, 12(1), 53-63.

Bargetz, B., Scheele, A. \& Schneider, S. (2019, November 19). Impulse aus dem feministischen Archiv: Zur Theoretisierung umkämpfter Solidaritäten. theorieblog.de.

Buck, E. \& Hönke, J. (2013). Pioniere der Prekarität - Ostdeutsche als Avantgarde des neuen Arbeitsmarktregimes. In R. Pates \& M. Schochow (Eds.), Der 'Ossi' (23-54). Wiesbaden: Springer Fachmedien.

Chattopadhyay, S., Wood, L. \& Cox, L. (Eds.). (2020). Organizing amidst Covid-19. Interface: A Journal for and about Social Movements, 12(1).

Colectiva Sembrar (2020, October 2). The future of pandemic solidarity. Redpepper, 229.

della Porta, D. (2020). How progressive social movements can save democracy in pandemic times. Interface: a journal for and about social movements, 12(1), 355-358.

du Gay, P., Evans, J. \& Redman, P. (2000). Identity: A Reader. London: SAGE.

Featherstone, D. (2012). Solidarity: Hidden Histories and Geographies of Internationalism. London: Zed Books.

Fiedlschuster, M. (2018). Globalization, EU democracy assistance and the world social forum: concepts and practices of democracy. Cham: Palgrave MacMillan.

Fiedlschuster, M. \& Reichle, L. R. (2020). Solidarity forever? Performing mutual aid in Leipzig, Germany. Interface: A Journal for and about Social Movements, 12(1), 317-325.

Haderer, M. (2018). "Economic Policies Are the Best Social Policies": West German Neoliberalism and the Housing Question After 1945. American Journal of Economics and Sociology, 77(1), 149-167.

hooks, bell. (2015). Feminist Theory: From Margin to Center. London: Routledge.

Joseph, J. (2002). Hegemony. A realist analysis. London: Routledge.

Kavada, A. (2020, June 12). Creating a hyperlocal infrastructure of care: COVID-19 Mutual Aid Groups. OpenDemocracy.net. 
Littler, J. (2013). Meritocracy as Plutocracy: The Marketising of 'Equality' Under Neoliberalism. New Formations, 80(80), 52-72.

Mayring, P. \& Fenzl, T. (2019). Qualitative Inhaltsanalyse. In N. Baur \& J. Blasius (Eds.), Handbuch Methoden der empirischen Sozialforschung (633-648). Wiesbaden: Springer Fachmedien.

Meißner, H. (2015). Eine Renaissance der Kapitalismuskritik? Feministische Suchbewegungen zur Erneuerung radikaler Emanzipationsvisionen. Feministische Studien, 33(1), 55-69.

Mühe, M. (2019, November 13). Bewegende Solidarität - Gedanken zur Solidarität im Kontext Sozialer Bewegungen. theorieblog.de.

Nuss, S. (2020, March 13). Unsere Vernunft, unser Herz füreinander. Rosa Luxemburg Stiftung.

Pleyers, G. (2020). The Pandemic is a battlefield. Social movements in the COVID-19 lockdown. Journal of Civil Society, 16(4), 295-312.

Putnam, R. D. (2000). Bowling alone: The collapse and revival of American community. New York: Simon \& Schuster.

Reichle, L. R. (2020a). Nachbarschaftliche Solidarität in der Krise? - Die Frage nach transformativem Potenzial von Nachbarschaftshilfe am Beispiel einer aktivistischen Fallstudie im Leipziger Osten. Corona Monitor.

Reichle, L. R. (2020b). Researching tenants' relations in a state of emergency-Relational polarization and its challenges for research. Centre for Urban Research on Austerity.

Reichle, L. R. \& Bescherer, P. (2021). 'Organizing with Tenants and Fighting Resentments - A Case Study from East Germany'. Radical Housing Journal, 3(1), forthcoming.

Schwiertz, H. \& Schwenken, H. (2020). Introduction: Inclusive solidarity and citizenship along migratory routes in Europe and the Americas. Citizenship Studies, 24(4), 405-423.

Sennett, R. (1973). The uses of disorder: Personal identity and city life. Harmondsworth: Penguin.

Sitrin, M. \& Colectiva Sembrar (Eds.). (2020). Pandemic Solidarity. London: Pluto Press.

Struwe, A. (2019, October 30). Was ist emanzipatorische Solidarität? theorieblog.de.

Wood, L. (2020). We're Not All in This Together. Interface: A Journal for and about Social Movements 12(1), 34-38. 
Online Sources - COVID numbers and initiatives' websites

Direct support Leipzig (2020). Ein Jahresrückblick und unsere Wunschliste. Retrieved from: https://leipzig.directsupport.care/de/newsfeed/ein-jahresrueckblick-und-unserewunschliste. Accessed 5 March 2021.

Robert Koch Institut (2021). COVID-19-Dashboard. Retrieved from: https://experience.arcgis.com/experience/478220a4c454480e823b17327b2bf1d4/page/page_1/. Accessed 5 March 2021.

Stiftung Ecken Wecken (2020). Bald geht's wieder los. Retrieved from: https://stiftungecken-wecken.de/projekte/corona-hilfe/blog/bald-gehts-wieder-los. Accessed 5 March 2021. 